\section{Australian export service}

\section{Canberra}

THE in vitro fertilization (IVF) technology that produced that first freeze-thaw embryo and donor-embryo babies will soon become in the United States. The vice-chancellor of Monash University in the state of Victoria announced in Melbourne last week that an months of discussion, to form a private company to establish clinics, train US doctors and make available the techniques developed at the Queen Victoria Medical Centre by Professor Carl Wood, Dr Alan Trounson and their colleagues.

The company will be called IVF Australia (IVFA) and its first clinic is expected to be set up in New York. In the absence of more stringent local laws controlling IVF, the services on offer will conform with the guidelines set out in the Infertility (Medical Procedures) Act (1984), which will be proclaimed by the Victorian State Parliament in the current session, having been deferred early last year when state opposition parties successfully blocked its passage.

The bill specifically forbids surrogate single women. freezing and storage. commercially available to infertile couples agreement had been reached, after 18

embryo transfer and the embryo flushing procedure known as lavage (or in vivo fertilization), where fertilization is carried out in the womb of one woman and the resulting embryo flushed out and transferred to the womb of another woman. To achieve bipartisan support, the Victorian Labor government was also obliged to deny IVF treatment to couples in a stable de facto relationship, except those already embarked on the Monash programme before the act comes into force. This appears to rule out all US de facto couples as well as

With more than 200 babies born at a time when most US clinics are closing down, the Melbourne researchers have brought several procedures to a high rate of success. The services offered will initially involve husband-and-wife gametes only, but will probably be extended to donor procedures as well, and will include embryo

The Victorian legislation is based principally on the recommendations of the Waller committee, set up to consider the ethical and legal issues raised by in vitro fertilization (see Nature 311, 288; 1984). The

\section{Hetero-solid growth}

\section{UK seeks to catch up}

A MUlti-million pound stimulus to British research in "low dimensional structures" over the next five years has been announced by the Science and Engineering Research Council (SERC). The programme is intended to enhance the United Kingdom's ability to compete scientifically and, in the longer term, industrially in the field of heterojunction semiconductors, and the new physics associated with such devices. SERC has already allocated $\mathbf{1 3 . 5}$ million to the scheme, which forms a part of the strategy for "core science" heralded by the council's Science Board last year (see Nature 309, 388; 1984).

Interest in low-dimensional structures has burgeoned over the past few years with the realization that they offer unprecedented opportunities for the study of semiconductor physics. In particular, the techniques of molecular beam epitaxy (MBE) and metal organic chemical vapour deposition (MOCVD) permit the construction of interleaved layers of semiconductor materials of precisely determined thickness - in many cases, only a few angstroms. In a superlattice, for example, layers of GaAs may alternate with GaA1As. The difference between the two materials in their respective energy gaps separating the valence and conduction bands can result in a two-dimensional layer of highly mobile electrons. The physics of such layers, in which unique phenomena such as fractional quantum effects and phase transitions have been observed, is one of the most active research areas, while the potential industrial spin-off with, for example, high-speed devices and optical communications and logic is vast.

To a considerable extent, British researchers have, until recently, had to confine their studies to "off the shelf" materials supplied by companies such as GEC, Philips and Plessey. As a result of the new initiative, however, university centres for material growth are being established, allowing researchers not only to design and grow materials as dictated by their research but also to study and improve the growth techniques themselves. For instance, a group at the University of Cambridge, with the collaboration of GEC and British Telecom, is developing in situ electron lithography during growth by MBE.

MBE work will also be carried out at the University of Nottingham and Imperial College, London, while an MOCVD facility is being developed at Oxford. A typical cost for the establishment of an MBE or MOCVD facility is anything up to $£ 500,000$. Industrial collaboration will involve part-sponsored studentships and funding of cooperative research grants. In such schemes, the company involved generally has right of first refusal of patentable discoveries, proceeds being shared with the public purse through the

Philip Campbell British Technology Group. act bans any form of cloning and any procedures where human gametes are mixed with those of an animal. A couple may nominate a (willing) donor, the woman's sister for example, but no donor may receive payment beyond normal expenses.

The Waller committee recommended that research on embryos should extend only over the first 14 days. The Victorian government has not yet formulated a full reply to the committee's recommendations but the draft legislation provides for a Standing Review and Advisory Committee to be created to consider requests for approval of research with embryos.

Where does the act leave the frozen Rios embryos (see Nature 309, 738; 1984), whose biological parents perished in an air crash, leaving no instructions for their ultimate disposition? According to the draft Victorian legislation as it now stands, the embryos would be made available to other couples on the IVF programme who would be told that the embryos are unlikely to grow to maturity because the methods used to freeze them were not as well developed as those now available. The prospective social parents would be supplied with nonidentifying information about the biological parents (the Rios) and if a person grown from one of the Rios embryos were to seek this information from the Victorian State Health Commission, it would also be non-identifying, subject to the discretion of the minister.

No development or discovery will be incorporated as part of IVFA's programme until approved by a Bioethics Committee which, in the manner of the Waller committee and the Standing Review and Advisory Committee, is likely to consist of lawyers, philosophers, social workers and medical researchers. The company will not for the time being have its own research and development function; the Monash University team, however, will continue to publish its research results. Where patentable discoveries emerge, care will be taken to enable proprietary rights to be secured but, under the agreement, patenting of medical procedures will not be permitted. The university has no equity in the company but will receive royalties. Members of the IVF team in Melbourne will remain employees of the university and may receive payment on a consulting basis.

Professor Wood says that the money for research generated by the royalty payments has become necessary to keep the team to. gether, given the low support accorded to the IVF programme in the past; ethical objections to profit derived from the ad vanced techniques would, if taken up, appear to apply to all private medicine. There could be no absolute guarantee, he says, that a US doctor trained in the new techniques would not start his own clinic offering procedures illegal in Victoria, but such a clinic would then not continue to enjoy support from the Melbourne IVF team, and a personal vetting scheme would also help to minimize this risk. Jeffrey Sellar 